\title{
Barriers and Enablers in Implementing Electronic Consultations in Primary Care: Scoping Review
}

Rebecca Baines, MSc; John Tredinnick-Rowe, PhD; Ray Jones, PhD; Arunangsu Chatterjee, PhD

University of Plymouth, Plymouth, United Kingdom

Corresponding Author:

Arunangsu Chatterjee, $\mathrm{PhD}$

University of Plymouth

Room 108 I 3 Endsleigh Place

Drake Circus

Plymouth,

United Kingdom

Phone: 441752586837

Email: arunangsu.chatterjee@plymouth.ac.uk

\section{Abstract}

Background: Often promoted as a way to address increasing demands, improve patient accessibility, and improve overall efficiency, electronic consultations are becoming increasingly common in primary care, particularly in light of the current COVID-19 pandemic. However, despite their increasing use, a theoretically informed understanding of the factors that support and inhibit their effective implementation is severely limited.

Objective: With this scoping review, we sought to identify the factors that support and inhibit the implementation of electronic consultations in primary care.

Methods: In total, 5 electronic databases (PubMed, Medline, Embase, CINAHL, and PsycINFO) were systematically searched for studies published in 2009-2019 that explored the impact and/or implementation of electronic consultations in primary care. Database searches were supplemented by reference list and grey literature searches. Data were analyzed using inductive thematic analysis and synthesized using Normalization Process Theory (NPT).

Results: In total, 227 articles were initially identified and 13 were included in this review. The main factors found to hinder implementation included awareness and expectations; low levels of engagement; perceived suitability for all patient groups, conditions, and demographics; cost; and other contextual factors. Reports of information technology reliability and clinical workload duplication (as opposed to reduction) also appeared detrimental. Conversely, the development of protocols and guidance; patient and staff education; strategic marketing; and patient and public involvement were all identified as beneficial in facilitating electronic consultation implementation.

Conclusions: This review highlights the need for proactive engagement with patients and staff to facilitate understanding and awareness, process optimization, and delivery of coherent training and education that maximizes impact and success. Although the necessity to use online methods during the COVID-19 pandemic may have accelerated awareness, concerns over workload duplication and inequality of access may remain. Future research should explore health inequalities in electronic consultations and their economic impacts from multiple perspectives (eg, patient, professional, and commissioner) to determine their potential value. Further work to identify the role of meaningful patient involvement in digital innovation, implementation, and evaluation is also required following the rapid digitization of health and social care.

(J Med Internet Res 2020;22(11):e19375) doi: $\underline{10.2196 / 19375}$

\section{KEYWORDS}

remote consultation; COVID-19; implementation science; primary health care; patient participation; referral and consultation

\section{Introduction}

With a $16 \%$ increase in the number of general practitioner (GP) consultations between 2007-2014 in England alone, primary care is considered to be at "saturation point" [1]. General practice is often described as facing increasing demand, reduced accessibility, and heightened patient dissatisfaction [2,3]. As a result, primary care providers are being increasingly encouraged to adopt alternative, more digitally focused methods of care 
provision [4], particularly in light of the recent COVID-19 outbreak. This drive toward digital platforms is reflected on an international scale [5-8], with digital platforms often promoted as a way to relieve pressures on existing services and improve accessibility, efficiency, and cost-effectiveness while simultaneously promoting self-management and patient-centered care $[1,3,4,9]$. However, critical exploration of these assumptions is severely limited.

Within the United Kingdom, prior to the COVID-19 pandemic, there were two main electronic consultation providers: askmyGP and eConsult, the latter of which was previously known as WebGP $[10,11]$. These systems are online triage tools designed to provide patients with an alternative way of contacting their GP practice [4]. For the purposes of this article, we define the term electronic consultations as an online service that enables patients to access advice and care from a primary care practitioner or staff member by combining preliminary health issues and symptom checking with appointment booking. These products are distinct from video-based consultations that a doctor might use, such as Babylon, AccuRx, or LIVI. In the United Kingdom, electronic consultations are also distinct from their use in North America as a video system to communicate between family doctors and specialists in hospitals.

While some research has explored the benefits of electronic consultations and the experiences of health care professionals using them, such work is often critiqued for its overreliance on pilot studies [3,4]. Other criticisms of existing literature also include a limited understanding of the cost implications for both health care professionals and patients [12-14], and a predominate focus on professional perspectives [1,15], with limited exploration of patient experiences and expectations [3,6,11]. Furthermore, of the limited research conducted, the majority of it has focused on the experience of using electronic consultations, as opposed to the practicalities of implementing such technology. Finally, in spite of their increasing use, a theoretically informed understanding of the factors that support or inhibit the implementation of electronic consultations is severely limited [4,5,8,11], particularly in a UK setting [16]. This review seeks to address this gap by identifying the factors that support and inhibit the implementation of electronic consultations in primary care using Normalization Process Theory (NPT) as a theoretical framework. This scoping review is well-timed given the rapidly increasing use of electronic consultations in light of the COVID-19 outbreak and the resulting mandatory shift toward total triage in primary care [4]. Although focused on general practice and electronic consultations, the implications of this review may be relevant to other digital forms of health and care technology and their subsequent implementation.

\section{Methods}

\section{Design}

A scoping review was conducted due to their ability to map existing evidence in an emerging field (such as electronic consultations), identify gaps in existing understanding, and incorporate different study designs that can be grouped together to evaluate a particular topic of interest $[17,18]$.

\section{Search Strategy}

As advised by an information specialist, 5 databases (PubMed, Medline, Embase, CINAHL, and PsycINFO) were systematically searched using the search terms "econsult" OR "electronic consultation" OR "WebGP" OR "non face-to-face consultations" OR "technology mediated consultations" AND "primary care" OR "GP” OR "general practice." Search terms were designed and reviewed using the Peer Review of Electronic Search Strategies (PRESS) guidance [19].

A grey literature search was also conducted to ensure sufficient inclusivity and coverage. Grey literature was defined as "that which is produced on all levels of government, academics, business and industry in print and electronic formats, but which is not controlled by commercial publishers" [20]. The peer-reviewed search strategy was also used in Google Scholar.

\section{Inclusion and Exclusion Criteria}

Research studies that explored the impact or implementation of electronic consultation platforms designed to be used by a primary care clinician and patient, published in the English language, of any study design (including opinion pieces and editorial letters) were included. Research studies that were not published in the English language or focused on electronic consultation platforms outside of primary care (eg, between non-primary care specialties) were excluded to retain a relevant focus of interest.

While the researchers aimed to be inclusive, due to limited resources, a sensitive translation of non-English texts could not be provided. Finally, to ensure only the most contemporary literature was included, a time limit was applied (January 1, 2009 , to January 31,2019$)$. Literature searches were conducted on February 1, 2019.

\section{Screening and Eligibility}

All identified articles were screened using a two-stage process. First, the title and abstract of all identified articles were reviewed independently by two researchers using the inclusion criteria outlined above. This process was facilitated using Rayyan, software for conducting reviews [21]. The full texts of potentially relevant articles were then reviewed for inclusion. Any disagreements were resolved through the inclusion of a third researcher. Database searches were also supplemented by reference list searches of included studies.

Data was extracted from the included studies independently by two reviewers using a pilot tested extraction form. Data extracted included author names, date of publication, setting, study type, sample, analysis method, and reported findings/author interpretations.

\section{Analysis}

Included studies were initially coded independently by two reviewers using inductive thematic analysis as outlined by Braun and Clarke [22]. Identified themes were then synthesized using NPT as outlined below by the same two reviewers.

\section{Synthesis}

Data was synthesized using NPT [23] as an analytical framework. NPT was originally developed to understand the 
embedding of new, particularly complex technologies in health care systems [23], providing a clear rationale for its inclusion in this research. As outlined by Murray [23], NPT is underpinned by four constructs that often operate simultaneously:

1. Coherence: how people make sense of a new technology/system/process.

2. Cognitive participation: how people engage with a new technology/system/process.

3. Collective action: how people make new technologies/systems/processes work in practice (or not).

4. Reflexive monitoring: how people assess the value of new technologies/systems/processes.

For the purposes of this article, we report findings on the first three domains of NPT (coherence, participation, and collective action). As previously mentioned, of the limited research previously conducted, most has focused on professional experiences (eg, reflexive monitoring). We therefore focus on the three remaining domains of NPT to avoid duplication.

\section{Quality Appraisal}

In line with scoping review practice [18], included studies were not quality appraised.

\section{Ethical Approval}

Participation in this research was entirely voluntary. All participants gave full informed consent. The University of Plymouth, Faculty of Health and Human Sciences (Reference number 18/19-1060) provided ethical approval.

\section{Results}

\section{Overview}

From the 227 articles initially identified, 13 were included for the purposes of this review (Figure 1). Table 1 summarizes the characteristics of the included studies.

Figure 1. PRISMA diagram of included studies. PRISMA: Preferred Reporting Items for Systematic Reviews and Meta-analyses.

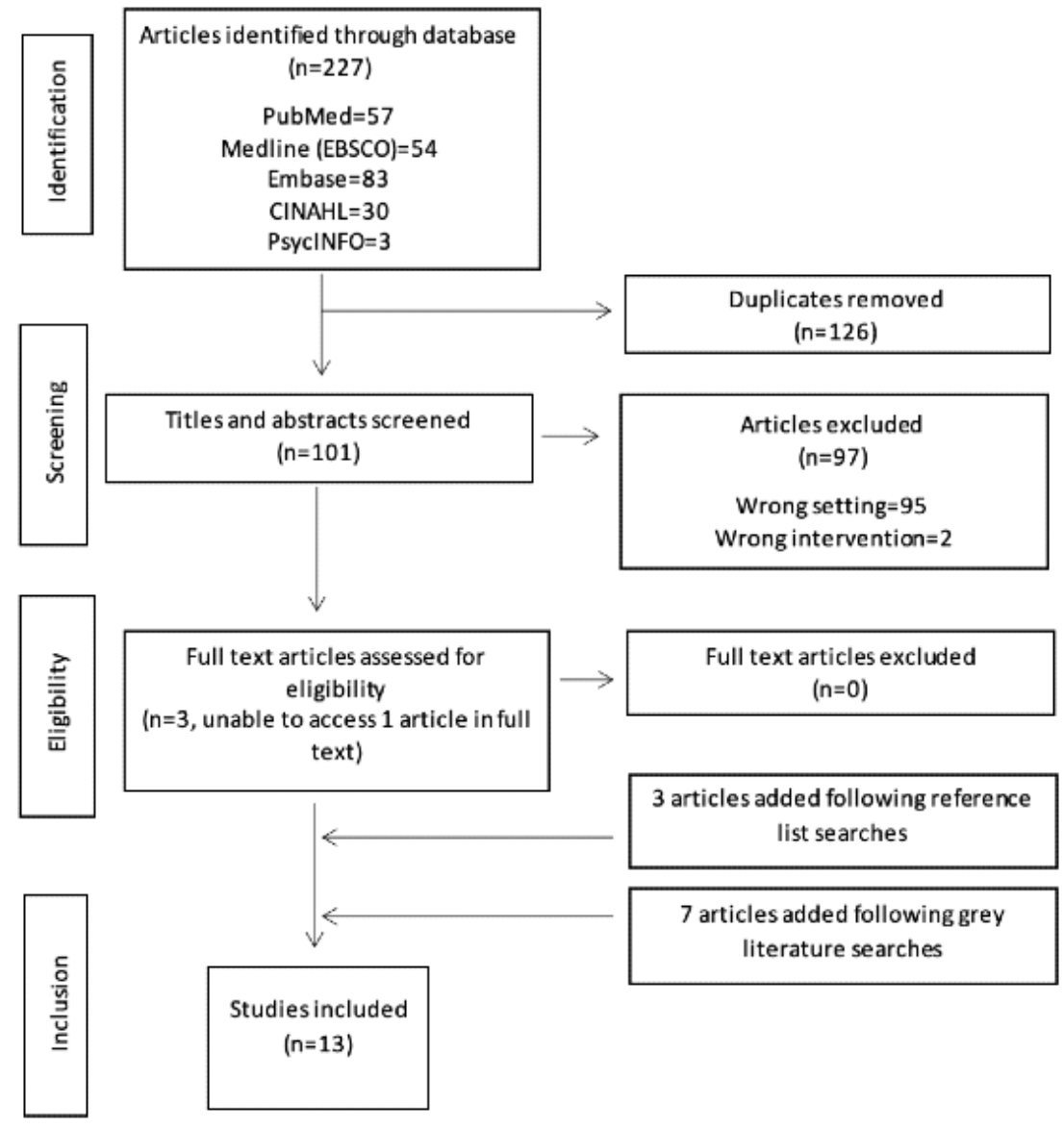


Table 1. Characteristics of included studies.

\begin{tabular}{|c|c|c|c|c|c|c|}
\hline Authors & Country & Study type & Intervention & Setting & Participants and databases & Analysis method \\
\hline $\begin{array}{l}\text { Atherton et } \\
\text { al, } 2018 \\
{[24]}\end{array}$ & $\begin{array}{l}\text { England } \\
\text { and Scot- } \\
\text { land }\end{array}$ & $\begin{array}{l}\text { Mixed methods case } \\
\text { design }\end{array}$ & $\begin{array}{l}\text { Alternatives to face-to- } \\
\text { face consultations }\end{array}$ & $\begin{array}{l}\text { General practices } \\
\text { with varied experi- } \\
\text { ence of implement- } \\
\text { ing alternatives to } \\
\text { face-to-face consulta- } \\
\text { tions }\end{array}$ & Patients and practice staff & $\begin{array}{l}\text { Descriptive statis- } \\
\text { tics, multivariate } \\
\text { analysis, and coding } \\
\text { of qualitative data } \\
\text { from EMIS Health }\end{array}$ \\
\hline $\begin{array}{l}\text { Banks et } \\
\text { al, 2018 [4] }\end{array}$ & $\begin{array}{l}\text { West of } \\
\text { England }\end{array}$ & Qualitative & eConsult & $\begin{array}{l}\text { General practices } \\
\text { that piloted an e- } \\
\text { consultation system } \\
\text { for } 15 \text { months dur- } \\
\text { ing } 2015 \text { and } 2016\end{array}$ & $\begin{array}{l}23 \text { semistructured inter- } \\
\text { views with staff members }\end{array}$ & $\begin{array}{l}\text { Thematic analysis of } \\
\text { interview data }\end{array}$ \\
\hline $\begin{array}{l}\text { Cowie et } \\
\text { al, } 2018 \\
{[25]}\end{array}$ & Scotland & Mixed methods & eConsult & $\begin{array}{l}11 \text { general practices } \\
\text { piloting eConsult }\end{array}$ & $\begin{array}{l}44 \text { semistructured practice } \\
\text { staff interviews, } 1 \text { focus } \\
\text { group ( } 4 \text { staff), and } 291 \\
\text { patient survey responses }\end{array}$ & $\begin{array}{l}\text { Health economics, } \\
\text { thematic analysis } \\
\text { and coding, patient } \\
\text { survey, descriptive } \\
\text { statistics }\end{array}$ \\
\hline $\begin{array}{l}\text { Carter et } \\
\text { al, } 2018[6]\end{array}$ & $\begin{array}{l}\text { South West } \\
\text { England }\end{array}$ & Mixed methods & WebGP & $\begin{array}{l}6 \text { GP practices in } \\
\text { Devon }\end{array}$ & $\begin{array}{l}\text { Six practices provided } \\
\text { consultations data; } 20 \text { GPs } \\
\text { completed case reports } \\
\text { (regarding } 61 \text { e-consults); } \\
81 \text { patients completed } \\
\text { questionnaires; } 5 \text { GPs and } \\
5 \text { administrators were inter- } \\
\text { viewed }\end{array}$ & $\begin{array}{l}\text { Statistical analysis } \\
\text { of surveys, thematic } \\
\text { analysis of interview } \\
\text { data }\end{array}$ \\
\hline $\begin{array}{l}\text { Farr et al, } \\
2018[3]\end{array}$ & $\begin{array}{l}\text { South West } \\
\text { England }\end{array}$ & Mixed methods & eConsult & 6 general practices & $\begin{array}{l}23 \text { practice staff inter- } \\
\text { views, patient survey data } \\
\text { for } 756 \text { e-consultations } \\
\text { from } 36 \text { practices }\end{array}$ & $\begin{array}{l}\text { Economic analysis } \\
\text { on usage and costs, } \\
\text { Normalization Pro- } \\
\text { cess Theory, induc- } \\
\text { tive thematic analy- } \\
\text { sis, patient survey } \\
\text { and record data sta- } \\
\text { tistical analysis }\end{array}$ \\
\hline $\begin{array}{l}\text { Ogden, } \\
2018[26]\end{array}$ & $\mathrm{N} / \mathrm{A}^{\mathrm{a}}$ & Opinion piece & Online consulting & N/A & N/A & Descriptive statistics \\
\hline $\begin{array}{l}\text { Marshall et } \\
\text { al, } 2018[8]\end{array}$ & N/A & Opinion piece & Online consulting & N/A & N/A & N/A \\
\hline $\begin{array}{l}\text { Casey et al, } \\
2017[1]\end{array}$ & N/A & $\begin{array}{l}\text { Mixed methods case } \\
\text { study }\end{array}$ & $\begin{array}{l}\text { Online consultation sys- } \\
\text { tem }\end{array}$ & $\begin{array}{l}\text { Inner-city general } \\
\text { practice }\end{array}$ & $\begin{array}{l}\text { Information technology } \\
\text { developers, clinicians, and } \\
\text { administrative staff }\end{array}$ & $\begin{array}{l}\text { Thematic and dis- } \\
\text { course analysis of } \\
\text { interview data }\end{array}$ \\
\hline $\begin{array}{l}\text { Edwards et } \\
\text { al, } 2017 \\
{[16]}\end{array}$ & $\begin{array}{l}\text { South West } \\
\text { of England }\end{array}$ & Observational study & eConsult & $\begin{array}{l}\text { South West of Eng- } \\
\text { land }\end{array}$ & $\begin{array}{l}\text { eConsult data obtained } \\
\text { from } 36 \text { general practices }\end{array}$ & $\begin{array}{l}\text { Economic analysis, } \\
\text { website analytics, } \\
\text { survey-based statisti- } \\
\text { cal analysis }\end{array}$ \\
\hline $\begin{array}{l}\text { Wise, } 2017 \\
{[10]}\end{array}$ & N/A & Opinion piece & Online consultations & N/A & N/A & N/A \\
\hline $\begin{array}{l}\text { Hanna et } \\
\mathrm{al}, 2012 \\
{[27]}\end{array}$ & Scotland & Qualitative & $\begin{array}{l}\text { Non-face-to-face consul- } \\
\text { tations }\end{array}$ & Scotland & $\begin{array}{l}20 \text { semistructured inter- } \\
\text { views with general practi- } \\
\text { tioners }\end{array}$ & $\begin{array}{l}\text { Thematic analysis of } \\
\text { interviews }\end{array}$ \\
\hline
\end{tabular}




\begin{tabular}{|c|c|c|c|c|c|c|}
\hline Authors & Country & Study type & Intervention & Setting & Participants and databases & Analysis method \\
\hline $\begin{array}{l}\text { Mair et al, } \\
2012 \text { [28] }\end{array}$ & N/A & Systematic review & $\begin{array}{l}\text { eHealth systems (only } \\
\text { information pertaining to } \\
\text { online consultations } \\
\text { recorded) }\end{array}$ & N/A & $\begin{array}{l}\text { MEDLINE, EMBASE, } \\
\text { CINAHL, PsycINFO, and } \\
\text { the Cochrane Library were } \\
\text { searched for reviews pub- } \\
\text { lished between January 1, } \\
\text { 1995, and March 17, } 2009 \text {. } \\
\text { Studies had to be systemat- } \\
\text { ic reviews, narrative re- } \\
\text { views, qualitative meta- } \\
\text { syntheses or meta-ethnogra- } \\
\text { phies of eHealth implemen- } \\
\text { tation }\end{array}$ & Evidence synthesis \\
\hline
\end{tabular}

$\begin{array}{lll}\begin{array}{l}\text { Hanna et } \\ \text { al, } 2011\end{array} & \text { Scotland } \quad \text { Mixed methods } & \begin{array}{l}\text { Non-face-to-face consul- Scotland } \\ \text { tations }\end{array} \\ {[15]} & & \end{array}$

600 practice manager questionnaire responses, 20 practice manager interviews
Chi-squared test from a survey, thematic analysis of interviews
${ }^{\mathrm{a}}$ N/A: not applicable.

As demonstrated in Table 1, most of the research published in the last two years has used a mixed methods design. There has been a particular focus on the introduction of electronic consultations in South West England and Scotland. Our results are presented in line with the three selected domains of NPT as outlined above. We begin by presenting the factors that inhibit implementation, followed by those that facilitate implementation.

\section{Factors That Inhibit Electronic Consultation Implementation}

\section{Coherence: What Factors Inhibit the Understanding of Electronic Consultations?}

\section{Awareness and Expectations}

A lack of understanding and awareness about the purpose of electronic consultation systems appears particularly problematic in their implementation and impact [24]. Patient understanding and awareness was reportedly mixed, with the effectiveness of electronic consultation advertising often called into question $[16,25]$. Patients were often not aware of alternative methods available to them, and how to access or operate such services $[16,24]$. Atherton suggests this is a matter for individual practices rather than policy directives [24].

A difference in staff and patient expectations regarding the appropriate use of electronic consultations was also reported [3]. This primarily related to the inappropriate use of electronic consultations to get a timelier face-to-face appointment as later discussed.

\section{Cognitive Participation: What Factors Inhibit How People Engage With Electronic Consultations?}

\section{Low Uptake}

Studies identified a low uptake as a further barrier to electronic consultation implementation [1,3,4,6,11,16,24]. Engagement levels were often reported to be much lower than expected [3]. For example, Banks et al [4] reported that only around $6 \%$ of practices used some form of electronic consultation. Similarly, Edwards et al [16] concluded that of the 36 practices reviewed, there was an average of 2 electronic consultations per 1000 patients per month. Such findings mirrored calculations by Cowie and colleagues [11]; the highest submission rate reported was almost 0.1 consultations per patient per year.

\section{Suitability for Certain Patient Groups, Conditions, and Demographics}

The suitability of electronic consultations for certain patient groups, conditions, and demographics was also called into question. Electronic consultations were considered more suitable for certain patient groups with discrete, "straightforward," or familiar ongoing treatment queries $[1,3,24,27]$. In comparison, face-to-face consultations were reportedly preferred for new, acute, or complex cases that required physical examination and/or regular monitoring [3,4,16,24,26]. As a result, some health care professionals expressed concern that patient groups including those with long-term conditions, multimorbidity, and/or mental health problems would be disadvantaged or unintentionally excluded from electronic consultation opportunities $[8,24]$. Some GPs repeatedly expressed concerns that introducing a new technology could create or widen existing inequalities in access to health care [3,27,29]. Atherton acknowledged the purposeful selection of patients by health care professionals, including receptionists and administrators, based on their assumptions of who they felt would be able to use electronic consultations appropriately [24], highlighting further concerns regarding unintentional or intentional exclusion.

In regard to demographics, included articles also suggested that women are almost twice as likely to use electronic consultation systems than men $[6,11,16]$. Younger patients are also more likely to engage with electronic consultation systems, with levels of engagement typically declining with age $[3,6,11,16,24]$. Levels of education, language [3], and employment were also shown to influence electronic consultation use [6,24,27].

\section{Contextual Factors: Practice Size, Deprivation, and Geographical Location}

Following this, a range of contextual factors including practice size, deprivation, and geographical location appeared to influence electronic consultation implementation and effect [29]. Hanna et al [29] suggested that the bigger the practice size, the more support available, including a website, an information 
technology (IT) manager, and a triage team, thereby influencing implementation efforts and sustainability [29].

\section{Cost}

Finally, cost was reported as a significant barrier to electronic consultation engagement and implementation [3,4], with limited evidence available to justify its associated expense [4,11]. As suggested by Farr et al [3], costs often prohibited long-term engagement with electronic consultation systems.

\section{Collective Action: What Factors Inhibit How People Work With Electronic Consultations?}

\section{Additional Time and Increased Workload}

In regard to how people work with electronic consultations (collective action), the majority of included studies reported an increase in clinician workload. This was often attributed to additional follow-up and/or face-to-face consultations due to a lack of sufficient information being provided $[1,4,6,11,16,27,28]$. Although one study acknowledged a potential benefit of having the clinical issue documented prior to a face-to-face appointment [4], this conclusion was contradicted by another article that found that follow-up appointments were typically longer than the national average (14.5 minutes versus 9.2 minutes for face-to-face) [16]. However, it is important to note that this disparity may be a result of a lack of GP continuity between electronic and follow-up consultations [3].

GPs also reported significant difficulties in establishing a patient's primary concern, following an inability to probe for further information $[3,4,16]$. Where reported, most electronic consultations resulted in either follow-up phone calls or face-to-face appointments, leading GPs to report a duplication in their workload, as opposed to a desired reduction $[1,3,6]$. The relatively low uptake of electronic consultation systems as previously described appeared to exacerbate this concern [11].

An increase in administrative workload was also reported, particularly the frequent need to contact patients regarding their electronic consultation outcome or to arrange a face-to-face or telephone appointment [11]. Cowie et al [11] reported that most practices made at least three attempts to contact patients, frequently reporting that contact could not be made. The use of a withheld number was suggested as a possible explanation. Some practices have developed methods to facilitate email contact as a solution to this problem, although issues of data security and protection remained a concern [11].

\section{Medicolegal Concerns}

Linked to concerns of data security and protection, medicolegal issues were also identified as a barrier to electronic consultation implementation and use. Concerns about the negotiation of clinical risk and diagnosis uncertainty were repeatedly expressed within the context of an increasingly litigious culture [8,27,29].

\section{Potential to "Game" the System}

As previously mentioned, some practice staff members expressed concern regarding "patients gaming the system" [4], with some reportedly using the system to achieve a timelier face-to-face appointment [3,4,6,11]. As reported by Banks et al [4] and others, staff often felt patients could get an appointment quicker using electronic consultation methods by circumventing traditional, often telephone-based appointment systems. The responsibility of the practice to contact the patient within a specified time frame, often by the end of the next working day $[4,6]$, as well as the content of marketing material [11], appeared to influence this perception.

\section{IT Reliability}

Finally, the reliability of technology was seen as a potential barrier to electronic consultation implementation and use. As reported by Hanna et al [29], some interviewees felt new IT systems were highly reliable, while others expressed concern about network availability and speed [27,29]. The interoperability of IT systems was also identified as influential in electronic consultation implementation [3,11], with competing or conflicting IT systems proving to be problematic.

\section{Factors That Facilitate Implementation}

In addition to the barriers outlined above, a number of facilitating factors were also identified in regard to electronic consultation implementation and use. Each are discussed in turn below.

\section{Coherence: What Factors Facilitate the Understanding of Electronic Consultations?}

\section{Protocols and Strategies}

First, the provision of protocols, strategies, and/or guidance including medicolegal advice was considered integral to the effective implementation of electronic consultations [11,26-28]. As identified by Cowie et al [11], the development of a clear strategy for introducing electronic consultations prior to any implementation was considered fundamental. Such protocols should be developed in collaboration with staff, patients, and electronic consultation champions (as discussed below) [11].

\section{Education}

Following this, quality patient and staff education on what electronic consultations are, what they are not, and when to use them was widely encouraged [3,6,11]. Cowie et al [11] recommended the construction of practice process diagrams along with clear objectives to facilitate staff understanding and awareness. An exploration of staff expectations was also considered integral [11].

\section{Focused Marketing}

Linked to the provision of education was a desire for more focused marketing $[6,11,26]$. Identified ways of promoting and marketing electronic consultations included leaflets, clear website positioning, posters, and recorded telephone messages [26]. As suggested by Ogden et al [26], recorded messages appeared particularly influential when recorded by a doctor.

\section{Patient and Public Involvement and Wider Network Development}

Combining the development of protocols, education, and marketing, patient and public involvement was also considered integral prior to and during any electronic consultation implementation to ensure acceptability and understanding $[3,11]$. Despite this, few practices reported engaging with patients in 
electronic consultation design, implementation, or evaluation [3]. This may explain some of the issues identified regarding patient understanding and awareness. Patient participation groups (PPGs) were identified as a beneficial resource for facilitating patient engagement, as were patient and public involvement workshops to provide feedback on electronic consultation systems, protocols, and experiences [11].

\section{Cognitive Participation: What Factors Support How Stakeholders Engage With Electronic Consultation?}

\section{Staff Training}

Moving on to cognitive participation, how stakeholders engaged with electronic consultations, adequate staff training that addressed how electronic consultations operate, how electronic consultations fit with existing practice processes, and individual responsibilities were considered essential for successful implementation [8,11,26-28].

\section{eConsultation Champions}

An electronic consultation champion was also considered helpful in ensuring effective implementation and engagement by promoting its use among patients and more reticent staff members [11,28]. However, the risk of jeopardizing staff and patient commitment by recruiting a critical champion was also acknowledged [28].

\section{Collective Action: What Factors Facilitate How Stakeholders Work With Electronic Consultations?}

\section{Strategic Marketing}

With regard to collective action (how stakeholders work with electronic consultations), strategic marketing or signposting was identified as a facilitating factor [3,6,11]. For example, signposting patients to use electronic consultations in certain situations where only remote GP access was likely to be required, including follow-up appointments, general administrative queries, repeat prescriptions, and general advice [11]. A more focused marketing strategy was considered to help improve overall efficiency, ensuring patients who might benefit from the service most were directly encouraged to engage with it [11].

\section{Notification Alerts}

In response to concerns of engaging in telephone "ping-pong," a desire for the development of an alerting system to inform patients of an incoming call following an electronic consultation request was also expressed [6,11]. Some practices already provide an estimated time for patient call-backs, clearly informing the patient that this may be from an unavailable or unknown number [11]. The development and effective incorporation of email contact was also expressed as a desirable solution to improving electronic consultation implementation and effectiveness [11], although this is reliant on the smooth integration of electronic consultations into existing IT systems as described below [28].

\section{Integration of Technology and Adequate Resourcing}

Mair et al [28] suggested clinicians may be deterred or become resistant to working with a system that adds complexity or requires additional effort and time. IT support was therefore considered integral to implementation [27], as was adequate resourcing, particularly financial support [28].

\section{Pairing of GPs With Patients}

Finally, the possibility of allocating electronic consultations to GPs who had had previous contact with the patient was seen as an effective way to facilitate implementation [3]. Table 2 provides a visual representation of the barriers and facilitators outlined in this review, according to the relevant domains of NPT.

Table 2. Identified barriers and facilitators to electronic consultation implementation and use.

\begin{tabular}{|c|c|c|}
\hline $\begin{array}{l}\text { Normalization Process } \\
\text { Theory domain }\end{array}$ & Barriers & Facilitators \\
\hline Coherence & $\begin{array}{l}\text { - Lack of understanding regarding its purpose and } \\
\text { intended use }\end{array}$ & $\begin{array}{l}\text { - Development of protocols, strategies, and guidance, includ- } \\
\text { ing medicolegal advice } \\
\text { - } \quad \text { Patient and staff education } \\
\text { - } \quad \text { Focused marketing } \\
\text { - Wider consultation with patients and staff members prior } \\
\text { to implementation }\end{array}$ \\
\hline Participation & $\begin{array}{ll}\text { - } & \text { Low uptake } \\
\text { - } & \text { Mainly administrative requests } \\
\text { - } & \text { Suitability for certain patient groups and conditions } \\
\text { - } & \text { Contextual factors including practice size, depriva- } \\
\text { - } & \text { Con, and geographical location } \\
\text { - } & \text { Limited patient involvement }\end{array}$ & $\begin{array}{l}\text { - Staff training } \\
\text { - Strategic/targeted patient use for those most likely to benefit } \\
\text { from electronic consultations } \\
\text { - } \quad \text { Electronic consultation champion }\end{array}$ \\
\hline Action & $\begin{array}{l}\text { - } \\
\text { - } \\
\text { - } \\
\text { - } \\
\text { - } \\
\text { - } \\
\text { - } \\
\text { Infedico potentional to to "game" the system }\end{array}$ & $\begin{array}{l}\text { Effective signposting informing patients of when to use } \\
\text { electronic consultation and when not } \\
\text { - } \quad \text { Notification alerts to alleviate administrative issues related } \\
\text { to contacting patients } \\
\text { - Integration of technology and adequate resourcing } \\
\text { - Pairing of general practitioner with prior patient contact }\end{array}$ \\
\hline
\end{tabular}




\section{Discussion}

\section{Summary}

This review addressed an identified gap in existing literature by developing a theoretically informed understanding of the factors that support and inhibit the practical implementation of electronic consultations in primary care $[4,5,8,11,16]$. Review findings suggest limited staff and patient awareness and understandings; low levels of engagement; perceived suitability for all patient groups, conditions, and demographics; cost; and other contextual factors including practice size, levels of deprivation, and geographical location are the main inhibitory factors of effectively implementing electronic consultations. As a result, the majority of included studies reported an increase in clinician and admin time, with many GPs reporting a duplication in workload, as opposed to the desired reduction. Findings from our review also identified a number of factors that could help facilitate the effective implementation of electronic consultations. These primarily focused on the provision of staff training, protocols, strategies, and guidance; enhanced patient awareness and education; strategic marketing; notification alerts, and patient and public involvement in the innovation, implementation, and evaluation stages.

\section{Comparison With Existing Literature}

Similar to existing research, the included articles reported a shortcoming of electronic consultations in their current form [4], with expressed skepticism regarding their financial investment [3]. Furthermore, many health care professionals expressed concern that electronic consultation duplicated administrative and clinical workloads. Such findings have been widely reported by a number of studies $[1,3,4,6,16]$. However, it is important to note that this may be due to the absence of supporting factors identified in this review and the relatively new emergence of electronic consultations. Further exploration of whether the presence of facilitating factors improves electronic consultation would be beneficial. Finally, we found a limited amount of research exploring electronic consultation experiences and impact from a patient perspective [3,6,11], identifying a further area for future research.

\section{Strengths and Limitations}

Strengths of this review include its exploration of both peer-reviewed and grey literature and novel application of a theoretical framework in the context of general practice and electronic consultations. However, its limitations must also be acknowledged. In line with scoping review practice, included articles were not quality appraised. The exclusion of non-English language texts may also have introduced research bias. Future research may benefit from a wider range of bibliographic databases, including technical databases such as IEEE. Exploration of any differences between private and free at the point of access service implementations/commissioning would also be beneficial.

\section{Implications for Practice}

With these in mind, the implications from this review are clear. First, the implementation of electronic consultations appears most effective when both patients and staff members are involved in the design, implementation, and evaluation of their processes and outcomes. Second, the rationale, purpose, and intended use of electronic consultations needs to be effectively communicated to both patients and staff members to ensure appropriate use and implementation. This could be best achieved through targeted marketing as well as meaningful patient involvement to facilitate patient understanding and acceptability. Third, marketing materials should reflect the reality of the product proposed to effectively manage people's expectations (ie, electronic consultation may not reduce workload to the extent originally promised). Efforts should also be made wherever possible to incorporate the factors identified as beneficial in electronic consultation implementation to achieve maximum success and impact. Finally, further work is required to explore the potential inequalities in electronic consultations, with evidence to suggest some patient groups may be disadvantaged or unintentionally excluded from electronic consultation opportunities $[8,23]$. Further exploration of the economic costs and benefits of electronic consultations from the perspective of patients, professionals, and commissioners would also be beneficial in informing current debates.

\section{Conclusion}

In conclusion, the implementation of electronic consultations in primary care can be facilitated by the development of protocols and strategies, patient and staff education, accurate and targeted education, and meaningful patient and public involvement. Efforts should be made wherever possible to incorporate factors identified as beneficial in facilitating electronic consultations to ensure maximum impact and success. Further research exploring the economic impacts of electronic consultations would be beneficial from a patient, professional, and commissioner perspective.

\section{Acknowledgments}

This research was commissioned by NHS Kernow Clinical Commissioning Group \& NHS Northern, Eastern, and Western Devon Clinical Commissioning Groups to evaluate the eConsult system in Devon and Cornwall. We would like to thank NHS Kernow Clinical Commissioning Group \& NHS Northern, Eastern, and Western Devon Clinical Commissioning Groups for the support and feedback.

\section{Conflicts of Interest}

None declared.

\section{References}


1. Casey M, Shaw S, Swinglehurst D. Experiences with online consultation systems in primary care: case study of one early adopter site. Br J Gen Pract 2017 Oct 09;67(664):e736-e743. [doi: 10.3399/bjgp17x693137]

2. Ross J, Stevenson F, Lau R, Murray E. Factors that influence the implementation of e-health: a systematic review of systematic reviews (an update). Implement Sci 2016 Oct 26;11(1):146 [FREE Full text] [doi: 10.1186/s13012-016-0510-7] [Medline: 27782832]

3. Farr M, Banks J, Edwards HB, Northstone K, Bernard E, Salisbury C, et al. Implementing online consultations in primary care: a mixed-method evaluation extending normalisation process theory through service co-production. BMJ Open 2018 Dec 19;8(3):e019966. [doi: 10.1136/bmjopen-2017-019966] [Medline: 29555817]

4. Banks J, Farr M, Salisbury C, Bernard E, Northstone K, Edwards H, et al. Use of an electronic consultation system in primary care: a qualitative interview study. Br J Gen Pract 2018 Jan;68(666):e1-e8. [doi: 10.3399/bjgp17X693509] [Medline: 29109115]

5. Atherton $\mathrm{H}$, Ziebland S. What do we need to consider when planning, implementing and researching the use of alternatives to face-to-face consultations in primary healthcare? Digit Health 2016 Nov 21;2:2055207616675559. [doi: 10.1177/2055207616675559] [Medline: 29942570]

6. Carter M, Fletcher E, Sansom A, Warren FC, Campbell JL. Feasibility, acceptability and effectiveness of an online alternative to face-to-face consultation in general practice: a mixed-methods study of webGP in six Devon practices. BMJ Open 2018 Feb 15;8(2):e018688. [doi: 10.1136/bmjopen-2017-018688] [Medline: 29449293]

7. Joschko J, Keely E, Grant R, Moroz I, Graveline M, Drimer N, et al. Electronic Consultation Services Worldwide: Environmental Scan. J Med Internet Res 2018 Dec 21;20(12):e11112 [FREE Full text] [doi: 10.2196/11112] [Medline: 30578187]

8. Marshall M, Shah R, Stokes-Lampard H. Online consulting in general practice: making the move from disruptive innovation to mainstream service. BMJ 2018 Mar 26;360:k1195. [doi: 10.1136/bmj.k1195] [Medline: 29581174]

9. Johnston DL, Murto K, Kurzawa J, Liddy C, Keely E, Lai L. Use of Electronic Consultation System to Improve Access to Care in Pediatric Hematology/Oncology. J Pediatr Hematol Oncol 2017 Oct;39(7):e367-e369. [doi: 10.1097/MPH.0000000000000833] [Medline: 28437292]

10. Wise J. Electronic consultations offer few benefits for GP practices, says study. BMJ 2017 Nov 06:j5141. [doi: 10.1136/bmj.j5141]

11. Cowie J, Calveley E, Bowers G, Bowers J. Evaluation of a Digital Consultation and Self-Care Advice Tool in Primary Care: A Multi-Methods Study. Int J Environ Res Public Health 2018 May 02;15(5):896 [FREE Full text] [doi: 10.3390/ijerph15050896] [Medline: 29724040]

12. Liddy C, Keely E, Afkham A. Faster Access, Better Care: A Guide to Establishing an eConsult Service. 2016. URL: https:/ /ruor.uottawa.ca/bitstream/10393/34968/1/Faster\%20Access\%2c\%20Better\%20Care.pdf [accessed 2020-10-28]

13. Anderson D, Villagra VG, Coman E, Ahmed T, Porto A, Jepeal N, et al. Reduced Cost Of Specialty Care Using Electronic Consultations For Medicaid Patients. Health Aff (Millwood) 2018 Dec;37(12):2031-2036. [doi: 10.1377/hlthaff.2018.05124] [Medline: $\underline{30633678]}$

14. Anderson D, Villagra V, Coman EN, Zlateva I, Hutchinson A, Villagra J, et al. A cost-effectiveness analysis of cardiology eConsults for Medicaid patients. Am J Manag Care 2018 Jan 01;24(1):e9-e16 [FREE Full text] [Medline: 29350511]

15. Hanna L, May C, Fairhurst K. The place of information and communication technology-mediated consultations in primary care: GPs' perspectives. Fam Pract 2012 Jun;29(3):361-366. [doi: 10.1093/fampra/cmr087] [Medline: 22006040]

16. Edwards HB, Marques E, Hollingworth W, Horwood J, Farr M, Bernard E, et al. Use of a primary care online consultation system, by whom, when and why: evaluation of a pilot observational study in 36 general practices in South West England. BMJ Open 2017 Nov 22;7(11):e016901. [doi: 10.1136/bmjopen-2017-016901] [Medline: 29167106]

17. Osman MA, Schick-Makaroff K, Thompson S, Featherstone R, Bialy L, Kurzawa J, et al. Barriers and facilitators for implementation of electronic consultations (eConsult) to enhance specialist access to care: a scoping review protocol. BMJ Open 2018 Sep 28;8(9):e022733. [doi: 10.1136/bmjopen-2018-022733] [Medline: $\underline{\text { 30269069] }}$

18. Tricco AC, Lillie E, Zarin W, O'Brien K, Colquhoun H, Kastner M, et al. A scoping review on the conduct and reporting of scoping reviews. BMC Med Res Methodol 2016 Feb 09;16:15 [FREE Full text] [doi: 10.1186/s12874-016-0116-4] [Medline: 26857112]

19. Sampson M, McGowan J, Cogo E, Grimshaw J, Moher D, Lefebvre C. An evidence-based practice guideline for the peer review of electronic search strategies. J Clin Epidemiol 2009 Sep;62(9):944-952. [doi: 10.1016/j.jclinepi.2008.10.012] [Medline: 19230612]

20. GreyNet. 4th International Conference on Grey Literature, New Frontiers in Grey Literature, 4-5 October 1999, Washington DC. Asian Libraries 1999 Jul;8(7):1. [doi: 10.1108/al.1999.17308gab.010]

21. Rayyan - a web and mobile app for systematic reviews. URL: https://rayyan.qcri.org/ [accessed 2020-10-28]

22. Braun V, Clarke V. Using thematic analysis in psychology. Qualitative Research in Psychology 2006 Jan;3(2):77-101. [doi: 10.1191/1478088706qp063oa]

23. Murray E, Treweek S, Pope C, MacFarlane A, Ballini L, Dowrick C, et al. Normalisation process theory: a framework for developing, evaluating and implementing complex interventions. BMC Med 2010 Oct 20;8:63 [FREE Full text] [doi: 10.1186/1741-7015-8-63] [Medline: 20961442] 
24. Atherton H, Brant H, Ziebland S, Bikker A, Campbell J, Gibson A, et al. The potential of alternatives to face-to-face consultation in general practice, and the impact on different patient groups: a mixed-methods case study. Health Serv Deliv Res 2018 Jun;6(20):1-200. [doi: 10.3310/hsdr06200] [Medline: 29889485]

25. Cowie J, Calveley E, Bowers G, Bowers J. Evaluation of a Digital Consultation and Self-Care Advice Tool in Primary Care: A Multi-Methods Study. Int J Environ Res Public Health 2018 May 02;15(5):896 [FREE Full text] [doi: 10.3390/ijerph15050896] [Medline: 29724040]

26. Ogden J. Online consultations: the future of NHS GP appointments? Prescriber 2018 Sep 19;29(9):27-30. [doi: 10.1002/psb.1703]

27. Hanna L, May C, Fairhurst K. The place of information and communication technology-mediated consultations in primary care: GPs' perspectives. Fam Pract 2012 Jun 17;29(3):361-366. [doi: 10.1093/fampra/cmr087] [Medline: 22006040]

28. Mair FS, May C, O'Donnell C, Finch T, Sullivan F, Murray E. Factors that promote or inhibit the implementation of e-health systems: an explanatory systematic review. Bull World Health Organ 2012 May 1;90(5):357-364. [doi: 10.2471/BLT.11.099424] [Medline: 22589569]

29. Hanna L, May C, Fairhurst K. Non-face-to-face consultations and communications in primary care: the role and perspective of general practice managers in Scotland. Inform Prim Care 2011;19(1):17-24 [FREE Full text] [doi: 10.14236/jhi.v19i1.789] [Medline: 22118332]

\title{
Abbreviations \\ GP: general practitioner \\ IT: information technology \\ NPT: Normalization Process Theory
}

\author{
Edited by G Eysenbach; submitted 15.04.20; peer-reviewed by S Schüssler, MA Bahrami; comments to author 12.06.20; revised \\ version received 26.06.20; accepted 26.07.20; published 12.11 .20 \\ Please cite as: \\ Baines R, Tredinnick-Rowe J, Jones $R$, Chatterjee A \\ Barriers and Enablers in Implementing Electronic Consultations in Primary Care: Scoping Review \\ J Med Internet Res 2020;22(11):e19375 \\ URL: https://www.jmir.org/2020/11/e19375 \\ doi: $10.2196 / 19375$ \\ PMID: 33035177
}

CRebecca Baines, John Tredinnick-Rowe, Ray Jones, Arunangsu Chatterjee. Originally published in the Journal of Medical Internet Research (http://www.jmir.org), 12.11.2020. This is an open-access article distributed under the terms of the Creative Commons Attribution License (https://creativecommons.org/licenses/by/4.0/), which permits unrestricted use, distribution, and reproduction in any medium, provided the original work, first published in the Journal of Medical Internet Research, is properly cited. The complete bibliographic information, a link to the original publication on http://www.jmir.org/, as well as this copyright and license information must be included. 